\title{
SELEKSI FITUR MENGGUNAKAN PENAMBANGAN DATA BERBASIS VARIABLE PRECISION ROUGH SET (VPRS) UNTUK DIAGNOSIS PENYAKIT JANTUNG KORONER
}

\author{
Dwi Normawati, Sri Winiarti \\ Program Studi Teknik Informatika, Fakultas Teknologi Industri, Universitas Ahmad Dahlan \\ Kampus III, Jln. Prof. Dr. Soepomo, S.H. Umbulharjo, Yogyakarta 55161 \\ e-mail: dwi.normawati@tif.uad.ac.id
}

\begin{abstract}
Coronary heart disease often causes death on human. This disease occurs when there is atherosclerosis (fat deposits) that blocks the flow of blood to the heart muscle in the coronary arteries. The gold standard method that doctors refer to diagnose coronary heart disease is the coronary angiography. However, this method is invasive, high risk and expensive. The purpose of this research is to perform a diagnosis of coronary heart disease based on computer using datamining by the feature selection method and by classifying the dataset of Cleveland heart disease.The feature selection method based on medical expert (MFS) and also the feature selection method based on computer, which is the feature selection method using the data mining method based on the Variable Precision Rough Set (VPRS) theory. Which is the development from the Rough Set Theory. This research begins by doing literature study about the feature selection method based on medical expert or motivated feature selection (MFS) and feature selection method based on computer that is the VPRS theory. To avoid missing features that the research considered by medical expert and by computer. In the end, the feature selection process based on VPRS and the combination of VPRS with MFS can improve the classification performance for diagnosing coronary heart disease significantly. This can be seen by the smaller number of rules generated and the values accuracy which is better than the classification with-out the feature selection.
\end{abstract}

Keywords: coronary heart disease; Cleveland; feature selection

\begin{abstract}
Abstrak
Penyakit jantung koroner merupakan penyakit yang banyak menyebabkan kematian pada manusia. Penyakit ini terjadi ketika terdapat atherosclerosis (timbunan lemak) yang menghalangi aliran darah ke otot jantung pada arteri koronaria. Metode gold standard yang menjadi rujukan para dokter untuk mendiagnosis penyakit jantung koroner adalah coronary angiography. Namun metode ini invasisve, mempunyai resiko tinggi dan mahal. Tujuan penelitian ini adalah melakukan diagnosis penyakit jantung koroner berbasis komputer menggunakan data mining dengan melakukan seleksi fiture dan melakukan klasifikasi pada dataset penyakit jantung Cleveland. Pada penelitian ini, menggunakan metode seleksi fitur berbasis pakar medis (MFS) dan juga menggunakan metode seleksi fitur berbasis komputer yaitu metode seleksi fiture menggunakan metode data mining berbasis teori Varible Precision Rough Set (VPRS) yang merupakan pengembangan dari teori Rough Set. Pada penelitian ini, studi literature tentang metode seleksi fiture berbasis pakar medis atau motivated feature selection (MFS) dan metode seleksi fitur berbasis komputer yaitu berbasis teori VPRS dilakukan. Penggabungan metode seleksi fitur berbasis pakar medis dan komputer juga dilakukan agar dapat menghindari terhapusnya fitur-fitur yang dianggap penting oleh pakar medis. Pada akhirnya, proses seleksi fitur basis komputer yaitu VPRS dan penggabungan VPRS dengan MFS mampu meningkatkan performa klasifikasi secara signifikan untuk mendiagnosis penyakit jantung koroner, dilihat dari lebih sedikitnya jumlah rule yang dihasilkan dan nilai hasil akurasi yang lebih baik dibandingkan dengan klasifikasi tanpa seleksi fitur.
\end{abstract}

Kata kunci: penyakit jantung coroner; Cleveland; seleksi fitur 
Jurnal IImu Teknik Elektro Komputer dan Informatika (JITEKI) Vol. 3, No. 2, Desember 2017

\section{Pendahuluan}

Penyakit jantung koroner adalah penyakit pembunuh yang paling di seluruh dunia. Jumlah pasien dengan penyakit jantung koroner meningkat setiap tahun, data dari Organisasi Kesehatan Dunia (WHO) menyatakan bahwa 17,5 juta orang diperkirakan meninggal pada tahun 2012 , yang mewakili $31 \%$ dari semua kematian global dan diperkirakan 7,4 juta disebabkan penyakit jantung koroner [1]. Gejala utama penyakit jantung koroner mendeteksi nyeri dada atau angina, tetapi cara ini sangat sulit dilakukan karena gejala pada pasien mungkin terlihat kabur dan nyeri dada juga bisa sering terjadi dalam kondisi yang mungkin tidak disertai dengan penyakit jantung koroner, ini kadang-kadang mengarah untuk diagnosis yang salah dengan penyakit lain [2]. Seiring dengan perkembangan teknologi informasi, banyak diagnosis penyakit jantung koroner dikembangkan menggunakan metode dibantu komputer [3]. Salah satu teknik untuk menangani sejumlah besar data adalah data mining [4]. Data mining di dunia medis memiliki potensi besar untuk menemukan pola tersembunyi dalam data set medis. Pola dapat digunakan untuk membantu dokter secara signifikan meningkatkan kualitas keputusan medis untuk mengungkapkan ada tidaknya penyakit [5]. Berbagai penelitian-penelitian lain berkaitan dengan diagnosis penyakit jantung koroner melalui algoritme data mining telah dilakukan. Peneliti menyajikan algoritme data mining berbasis rules dalam mendiagnosis penyakit jantung koroner. Algoritme berbasis rules dipilih karena menghasilkan aturan/rules yang sederhana tetapi memiliki akurasi yang cukup tinggi [6]. Metode seperti RIPPER [7][8], Artificial Neural Network (ANN) [9], Decision Tree [10] diusulkan untuk mendiagnosis penyakit jantung koroner. Pada diagnosis medis, reduksi data merupakan masalah yang penting. Data medis sering mengandung sejumlah fitur yang tidak relevan, redundant, dan sejumlah kasus yang relative sedikit sehingga mempengaruhi kualitas diagnosis penyakit [11]. Oleh karena itu, proses seleksi fitur dilakukan untuk menyeleksi fitur-fitur yang relevan pada data medis. Proses seleksi fitur diusulkan dalam banyak penelitian untuk meningkatkan akurasi pada proses diagnosis penyakit jantung koroner. Jumlah data riwayat medis pasien yang berkaitan dengan penyakit jantung koroner didunia ini semakin hari semakin bertambah banyak, namun disisi lain dengan jumlah data yang besar terdapat data yang kurang relevan. Untuk mengatasi permasalah tersebut teori rough set diusulkan oleh Pawlak [12]. Teori rough set mampu menangani dan menganalisa data dan menemukan pengetahuan dari data yang tidak lengkap, tidak tepat dan ambigu. Dengan kata lain, pendekatan rough set mampu menemukan pola data dari data yang tidak sempurna. Namun dalam perkembangannya teori rough set memiliki banyak kekurangan ketika digunakan dalam data mining yaitu masalah analisis klasifikasi karena terkadang informasi yang tersedia hanya dapat memenuhi untuk klasifikasi parsial [13], maka Ziarko memperkenalkan suatu model baru yaitu Variable Precision Rough Set (VPRS).

Penelitian menggunakan metode VPRS untuk kasus diagnosis penyakit jantung koroner telah dilakukan untuk menemukan pola data berupa rules berbasis klasifikasi [14], menghasilkan aturan/rules yang jumlahnya lebih sedikit dibandingkan dengan metode rough set dan rules yang dihasilkan oleh VPRS lebih mudah dipahami dan apabila dilakukan reduksi rules maka nilai akurasi justru menurun [15]. Diagnosis Penyakit Jantung Koroner dengan klasifikasi VPRS mengahasilkan nilai akurasi $75,22 \%$ [12] ujicoba dilakukan dengan melakukan pengacakan data sebanyak 30 kali, akan tetapi performa akurasi setiap rule tidak diketahui.

Oleh karena itu, penelitian tentang menggunakan data mining berbasis VPRS dilakukan untuk solusi seleksi fitur meningkatkan performa keakurasian diagnosis penyakit jantung koroner. Pada penelitian ini diteliti metode seleksi fitur pada data set penyakit jantung koroner dari Repository Machine Learning UCI AZZAASW untuk performa diagnosis. Diharapkan hasil diagnosis dari penelitian ini mampu memberikan masukan kepada dokter sebelum melakukan uji coronary angiography sehingga dapat menghindari prosedur invasive, berisiko dan mahal.

\section{Data}

Dalam penelitian ini, 303 data data set Cleveland Penyakit Jantung dari UCl repository pembelajaran mesin memiliki 7 data nilai yang hilang. Data dari nilai-nilai yang hilang dihapus agar tidak mempengaruhi hasil klasifikasi. Data set Cleveland Penyakit Jantung terdiri dari 14 atribut. Dua kelas data set ini adalah tidak adanya dan adanya penyakit jantung. Tabel 1 menggambarkan atribut di Cleveland penyakit jantung data set [16]. 
Jurnal IImu Teknik Elektro Komputer dan Informatika (JITEKI)

Vol. 3, No. 2, Desember 2017

Tabel 1. Keterangan data set penyakit jantung cleveland

\begin{tabular}{|c|c|c|}
\hline Nama Atribut & Deskripsi Atribut & Keterangan \\
\hline Age & Age & Numerik \\
\hline Sex & Sex & 0: Perempuan, 1: Laki-laki \\
\hline$C p$ & Chest pain type & $\begin{array}{l}\text { 1: typical angina; } 2 \text { : atypical angina; } 3 \text { : } \\
\text { non-anginal pain; } \\
\text { 4: asymptomatic }\end{array}$ \\
\hline Trestbps & Resting blood pressure & Numerik \\
\hline Chol & Serum kolesterol & Numerik \\
\hline Fbs & Fasting blood sugar $>120 \mathrm{mg} / \mathrm{dl}$ & $0:$ false; 1 : true \\
\hline Restecg & Hasil ECG selama istirahat & $\begin{array}{l}\text { 0: normal; 1: abnormal (memiliki kelainan } \\
\text { gelombang ST-T); } 2 \text { : Hipertrofil ventrikel }\end{array}$ \\
\hline Thalac & $\begin{array}{l}\text { Detak jantung maksimal yang } \\
\text { dicapai }\end{array}$ & Numeric \\
\hline Exang & $\begin{array}{l}\text { Ukuran boolean yang menunjukan } \\
\text { apakah latihan angina industri } \\
\text { terjadi }\end{array}$ & 0: No, and 1: Yes \\
\hline Oldpeak & $\begin{array}{l}\text { Segment ST yg diperoleh dari } \\
\text { latihan relatif terhadap istirahat }\end{array}$ & Numerik \\
\hline Slope & $\begin{array}{l}\text { Kemiringan segmen ST untuk } \\
\text { latihan maksimal (puncak). }\end{array}$ & 1: upsloping; 2: flat; 3: downsloping \\
\hline $\mathrm{Ca}$ & $\begin{array}{l}\text { Jumlah vessel utama yang } \\
\text { diwarnai oleh fluoroskopi }\end{array}$ & $0,1,2$ and 3 \\
\hline Thal & Thal & $\begin{array}{l}\text { 3: normal; 6: cacat tetap; } 7 \text { : cacat } \\
\text { reversible }\end{array}$ \\
\hline
\end{tabular}

\section{Metodologi}

Secara umum ada 6 tahapan yang dilakukan pada penelitian ini yaitu pengumpulan data set Cleveland, preprocessing data set, diskritisasi data set, pembangkitan aturan/rule dari data set, seleksi fitur berbasis klasifikasi data set, dan evaluasi performa. Tujuan penelitian ini dilakukan untuk menganalisa performa seleksi fitur berbasis klasifikasi untuk memperoleh fiturfitur tebaik dalam mendiagnosis penyakit jantung koroner. Jalan penelitan terdiri dari beberapa langkah seperti yang ditunjukan pada diagram alir penelitian di Gambar 1.

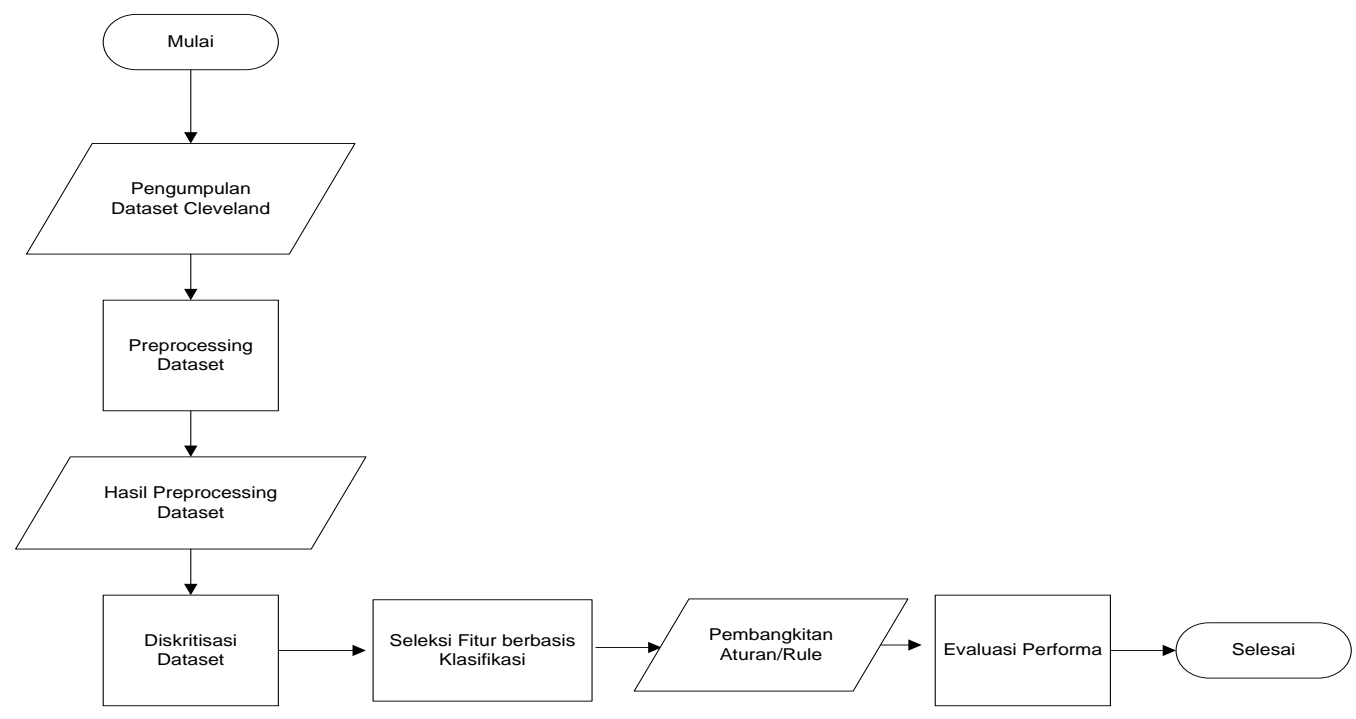

Gambar 1. Diagram alir penelitian

\subsection{Prapengolahan Data}

Prapengolahan data adalah langkah pertama dalam mendiagnosis penyakit jantung koroner. Proses data prapengolahan pada penelitian ini akan terbagi menjadi dua langkah yaitu 
data cleaning dan konversi data multiclass menjadi binary class. Pada proses data cleaning dilakukan penghapusan data yang missing values. Missing Value merupakan permasalahan yang sering ditemukan dalam menangani data medis. Pada data set Cleveland penyakit jantung koroner terdiri dari 303 instances, terdapat 7 instances yang memiliki missing values. Kemudian proses konversi data multiclass menjadi binary class dilakukan dengan mengasumsikan bahwa satu kelas positif yaitu sehat $(0)$ dan empat kelas lainnya menjadi satu kelas negatif yaitu sakit (1). Konversi data multiclass menjadi binary class dilakukan karena metode klasifikasi yang digunakan merupakan metode klasifikasi yang hanya menggunakan data biner.

\subsection{Diskritisasi Data}

Diskretisasi merupakan suatu proses konversi data tipe numerik menjadi tipe diskrit [11]. Nilai-nilai diskrit memiliki sejumlah batas interval dalam sebuah spectrum numerik, sedangkan nilai-nilai numerik tak terhingga banyaknya. Dengan proses diskretisasi data dapat dikurangi, disederhakan untuk pengguna dan para ahli, serta fitur diskrit lebih mudah dipahami, digunakan dan dijelaskan pada algoritme machine learning [17]. Pada penelitian ini proses diskritisasi data menggunakan Entropy/MDL (Minimum Description Length) yaitu metode diskretisasi yang diperkenalkan oleh J. Dougherty, R. Kohavi, and M. Saham. Metode ini didasarkan pada partisi secara rekursif pada nilai-nilai setiap atribut sehingga hasil pengukuran entropy dapat dioptimalkan. MDL atau Minimum Description Length mendefinisikan kapan berhentinya proses partisi. Nilai-nilai yang hilang (missing values) diabaikan dalam pencarian pemotongan. Jika tidak ada pemotongan yang ditemukan untuk sebuah atribut, atribut yang tersisa tidak diproses [17].

\subsection{Seleksi Fitur}

Seleksi fitur berbasis komputer dilakukan unutk mereduksi data Cleveland dan juga memilih fitur-fitur yang relevan terhadap hasil keputusan diagnosis penyakit jantung koroner. Pada penelitian ini digunakan dua jenis seleksi fitur yaitu berbasis komputer dan berbasis pakar medis. Seleksi fitur dilakukan dengan cara mereduksi fitur-fitur dengan metode seleksi fitur VPRS dan menggabungkan metode seleksi fitur berbasis pakar medis (MFS) agar dapat menghindari terhapusnya fitur-fitur yang dianggap penting oleh pakar medis untuk diagnosis penyakit jantung koroner. Pada penelitian ini untuk seleksi fitur dengan metode VPRS menggunakan software ROSE2.

\subsubsection{Seleksi Fitur berbasis Pakar Medis}

Seleksi fitur berbasis pakar medis atau motivated feature selection (MFS) didasarkan pada pengetahuan yang dimiliki oleh pakar medis. Pada kasus penyakit jantung koroner, pakar medis menentukan delapan faktor signifikansi medis yang berpengaruh dalam proses diagnosis. Delapan faktor tersebut adalah age, chest pain type(angina, abnang, notang, asympt), resting blood pressure, cholesterol, fasting blood sugar, resting heart rate (normal, abnormal, ventricular hypertrophy), maximum heart rate dan exercise induced angina [18]. Delapan faktor tersebut digunakan sebagai seleksi fitur berbasis pakar medis.

\subsubsection{Seleksi Fitur berbasis Variable Precision Rough Set (VPRS)}

Model VPRS merupakan kelanjutan dari model rough set klasik, yang diusulkan untuk menganalisis dan mengidentifikasi pola data yang mewakili trend statistic yang lebih fungsional [19]. VPRS berkaitan dengan klasifikasi parsial dengan memperkenalkan parameter presisi $\beta$. Ziarko mendefinisikan nilai $\beta$ sebagai kesalahan klasifikasi dan berkisar dalam nilai $0 \leq \beta<0,5$. Procedures Prosedur model VPRS memiliki 4 (empat) langkah sebagai berikut yaitu langkah ke1: Memilih nilai parameter presisi $\beta$, ke-2: Mencari himpunan penuh dari $\beta$-reduct, ke-3: Menghapus duplikat objek, ke-4: Rule extraction [13]. VPRS adalah pendekatan untuk analisis data yang bergantung pada 2 (dua) konsep dasar yaitu $\beta$-lower dan $\beta$-upper approximations yang dapat disajikan dalam persamaan sebagai berikut.

$$
\begin{aligned}
& \underline{C}_{\beta}(D)=\bigcup_{1-P_{r}\left(Z \mid x_{i}\right) \leq \beta}\left\{x_{i} \in E(P)\right\} \\
& \bar{C}_{\beta}(D)=\bigcup_{1-P_{r}\left(Z \mid x_{i}\right)<1-\beta}\left\{x_{i} \in E(P)\right\}
\end{aligned}
$$


dimana $E(P)$ menunjukan sebuah himpunan kelas-kelas ekuivalen, dan kondisi kelas berdasarkan subset atribut $P$, sedangkan $Z \subset E(D)$,

$$
P_{r}\left(Z \mid x_{i}\right)=\frac{\operatorname{Card}\left(Z \cap x_{i}\right)}{\operatorname{Card}\left(x_{i)}\right.}
$$

Menurut [20], ukuran quality of classification untuk model VPRS dapat didefinisikan dengan persamaan sebagai berikut :

$$
\gamma(P, D, \beta)=\frac{\operatorname{Card}\left(\bigcup_{1-P_{r}\left(Z \mid x_{i}\right) \leq \beta}\left\{x_{i} \in E(P)\right\}\right.}{\operatorname{Card}(U)}
$$

dimana $Z \subset E(D)$ dan $P \subseteq C$, untuk nilai $\beta$ tertentu. Nilai persamaan (2-5) mengukur proporsi obyek pada himpunan semesta $(U)$ untuk klasifikasi berdasarkan atribut keputusan $D$, dan memungkinkan untuk nilai $\beta$ tertentu.

Prosedur untuk menghasilkan aturan keputusan dari suatu sistem informasi dilakukan dengan 2 (dua) langkah utama sebagai berikut: Langkah ke-1: Pemilihan himpunan terkecil yang terbaik dari atribut-atribut (contoh: pemilihan nilai $\beta$-reduct) and Langkah ke-2: Penyederhanaan sistem informasi dapat dicapai dengan menjatuhkan nilai-nilai tertentu dari atribut yang tidak perlu untuk sistem informasi. Ziarko [21] mengindikasikan bahwa setiap himpunan terkecil atribut dianggap sebagai kelompok atribut alternatif yang dapat digunakan sebagai pengganti semua atribut yang tersedia di pengambilan keputusan berbasis kasus. Kesulitan utama adalah bagaimana memilih nilai $\beta$-reduct yang optimal. Untuk kasus tersebut ada dua pendekatan yang dapat digunakan. Pendekatan pertama, $\beta$-reduct dengan jumlah atribut paling sedikit yang dipilih, sedangkan pendekatan kedua, $\beta$-reduct yang memiliki jumlah terkecil kombinasi dari nilai-nilai atributnya yang dipilih.

\subsection{Pembangkitan Aturan/Rule IF-THEN}

Langkah selanjutnya adalah melakukan proses pembangkitan aturan-aturan (rule generation). Sebelum dilakukan pembangkitan aturan (rule generation), data set hasil diskritisasi dibagi menjadi dua yaitu data set latih (2/3 bagian) dan data set uji (1/3 bagian) dengan metode stratifikasi. Pada penelitian ini menggunakan metode pembangkitan aturan VPRS dengan menggunakan toolkits ROSE2.

Diagnosis penyakit jantung koroner berbasis komputer dilakukan dengan cara mengklasifikasikan aturan-aturan (Rules) yang dihasilkan pada proses pembangkitan aturan IFTHEN terhadap objek data set uji, kemudian menghitung nilai akurasi dengan menggunakan confusion matrix.

\subsection{Evaluasi Performa}

Evaluasi performa dilakukan dengan menganalisis performa klasifikasi. Klasifikasi merupakan pemetaan dari instance ke class prediksi [22]. Confusion matrix adalah alat visualisasi yang digunakan untuk menyajikan performa klasifikasi yang berisi informasi tentang hasil aktual dan hasil prediksi yang dilakukan oleh sistem. Pada penelitian ini evaluasi performa dilakukan dengan metode VPRS dengan menggunakan tiga performa yaitu akurasi, sensitivitas dan spesifisitas, dengan mengguanakan confusion matrix hasil klasifikasi, sehingga diperoleh hasil seleksi fitur terbaik.

Perbandingan performa metode klasifikasi dengan menggunakan tiga performa yaitu akurasi, sensitivitas dan spesifisitas. Dengan confusion matrix dapat diketahui perbandingan 4 kategori yang ditunjukan pada Tabel 2 .

Tabel 2. Confusion matrix hasil klasifikasi

\begin{tabular}{llcc} 
& \multicolumn{3}{c}{ Predicted } \\
\hline \multirow{3}{*}{ Actual } & \multicolumn{3}{c}{ Negative } \\
\cline { 2 - 4 } & Negative & $T N$ & Positive \\
\cline { 2 - 4 } & Positive & $F N$ & $F P$ \\
\hline
\end{tabular}


Jurnal IImu Teknik Elektro Komputer dan Informatika (JITEKI)

Vol. 3, No. 2, Desember 2017

Persamaan (3-1) memberikan formula untuk menghitung nilai akurasi.

Dimana:

$$
\text { Akurasi }=\frac{\mathrm{TP}+\mathrm{TN}}{\mathrm{TP}+\mathrm{FP}+\mathrm{TN}+\mathrm{FN}}
$$

TP: True positive (banyaknya data positif yang terprediksi sehat/positif)

TN: True Negative (banyaknya data negatif yang terprediksi sakit/negatif)

FP: False Positive (banyaknya data positif yang terprediksi sakit/negatif)

FN: False Negative (banyaknya data negatif yang terprediksi sehat/positif)

\section{Hasil dan Pembahasan}

Dalam penelitian, 296 data yang digunakan dari data set Cleveland penyakit jantung. Data di diskritisasi dengan menggunakan software ROSETTA, seleksi fitur dengan metode VPRS menggunakan software ROSE2, pembangkitan aturan/rule IF-THEN menghasilkan rule menggunakan software VPRS, dan proses klasifikasi dihitung secara manual dengan menggunakan Microsoft Excel.

\subsection{Data Preprocessing}

Langkah pertama dalam data prapengolahan adalah proses data cleaning. Proses data cleaning yaitu menghapus data yang ber-missing value dilakukan secara manual. Data set penyakit jantung Cleveland terdiri dari 303 instances dan terdapat 7 intances yang ber-missing values akan dihapus, sehingga data set yang digunakan pada penelitian ini sebanyak 296 instances.

Tabel 3. Karakteristik data set cleveland sesudah cleaning data

\begin{tabular}{ccccc}
\hline Dataset & Kelas Positif & $\begin{array}{c}\text { Jumlah } \\
\text { instance kelas } \\
\text { positif }\end{array}$ & $\begin{array}{c}\text { Jumlah } \\
\text { instance kelas } \\
\text { negative }\end{array}$ & $\begin{array}{c}\text { Jumlah total } \\
\text { instance }\end{array}$ \\
\hline H-0 & Sehat & 160 & 136 & 296 \\
Sick-1 & Sakit1 & 53 & 244 & 296 \\
Sick-2 & Sakit2 & 35 & 261 & 296 \\
H-0 & Sehat & 160 & 136 & 296 \\
Sick-1 & Sakit1 & 53 & 244 & 296 \\
\hline
\end{tabular}

Langlah kedua adalah mengkonversi data set multiclass menjadi binary class. Data set Cleveland memiliki lima kelas yaitu H-0, Sick-1, Sick-2, Sick-3, dan Sick-4 $(0,1,2,3,4)$, proses konversi data multiclass menjadi binary class dilakukan dengan mengasumsikan bahwa satu kelas positif yaitu sehat (0) dan empat kelas lainnya menjadi satu kelas negatif yaitu sakit (1).

Tabel 4. Karakteristik data set cleveland sesudah konversi data

\begin{tabular}{ccccc}
\hline Dataset & Kelas Positif & $\begin{array}{c}\text { Jumlah } \\
\text { instance kelas } \\
\text { positif }\end{array}$ & $\begin{array}{c}\text { Jumlah } \\
\text { instance kelas } \\
\text { negatif }\end{array}$ & $\begin{array}{c}\text { Jumlah total } \\
\text { instance }\end{array}$ \\
\hline Health & Sehat & 160 & 136 & 296 \\
Sick & Sakit & 136 & 160 & 296 \\
\hline
\end{tabular}

\subsection{Diskritisasi Data dan Nilai Parameter Presisi}

Langkah berikutnya adalah data diskritisasi yaitu mengubah tipe data dari atribut dari numerik ke diskrit. Beberapa atribut dengan jenis numerik yang memiliki Cleveland data set adalah usia, trestbps, chol, thalach, oldpeak dan ca, mereka berubah menjadi tipe diskrit menggunakan algoritma Entropi / MDL. Tabel 5 menunjukkan hasil data diskritisasi.

Tabel 5. Hasil diskretisasi data set

Atribut-atribut bertipe numerik

\begin{tabular}{cllllll}
\hline & \multicolumn{1}{c}{ Age } & Trestbps & \multicolumn{1}{c}{ Chol } & Thalach & Oldpeak & Ca \\
\cline { 2 - 6 } Nilai & {$\left[{ }^{*}, 71\right)$} & {$\left[{ }^{*}, 186\right)$} & {$\left[{ }^{*}, 276\right)$} & {$\left[{ }^{*}, 148\right)$} & {$\left[{ }^{*}, 2.5\right)$} & $\left.{ }^{*}, 3\right)$ \\
Diskritisasi & {$[71,77)$} & {$\left[186,{ }^{*}\right)$} & {$[276,277)$} & {$[148,151)$} & {$[2.5,2.7)$} & {$\left[3,{ }^{*}\right)$} \\
& {$\left[77,{ }^{*}\right)$} & & {$[277,280)$} & {$[151,162)$} & {$[2.7,3.1)$} &
\end{tabular}


Jurnal IImu Teknik Elektro Komputer dan Informatika (JITEKI)

Vol. 3, No. 2, Desember 2017

$\begin{array}{lll}{[280,295)} & {[162,170)} & {[3.1,3.5)} \\ {[295,299)} & {[170,172)} & {[3.5,3.6)} \\ {[299,301)} & {[172,175)} & {[3.6,4.3)} \\ {[301,319)} & {[175,176)} & {\left[4.3,{ }^{*}\right)} \\ {[319,320)} & {[176,178)} & \\ {[320,322)} & {[178,183)} & \\ {[322,324)} & {[183,195)} & \\ {[324,326)} & {[195,199)} & \\ {[326,338)} & {\left[199,{ }^{*}\right)} & \\ {[338,341)} & \\ {[341,342)} & \\ {[342,348)} & \\ {[348,354)} & \\ {[354,401)} & & \\ {[401,413)} & & \\ {\left[413,{ }^{*}\right)} & \end{array}$

Setelah dilakukan diskritisasi data, langkah selanjutnya adalah menentukan nilai parameter presisi diperoleh dengan menghitung rata-rata nilai akurasi dari validasi basic minimal covering dengan menggunakan toolkit ROSE2. Setiap prosesnya didapat nilai rata-rata akurasi yang selalu berubah, maka pada penelitian ini dilakukan perhitungan nilai sebanyak 30 kali untuk setiap nilai $\beta$. Nilai $\beta$ yang diuji yaitu nilai yang didefinisikan oleh Ziarko yaitu $0 \leq \beta<$ 0,5 dengan selisih masing-masing setiap nilai $\beta$-nya adalah 0,05 .

Tabel 6. Rata-rata nilai validasi basic minimal covering untuk mencari nilai $\beta$

\begin{tabular}{|c|c|c|c|c|c|c|c|c|c|c|}
\hline \multirow{2}{*}{$\begin{array}{c}\text { Percobaan } \\
\text { Ke- }\end{array}$} & \multicolumn{10}{|c|}{ Nilai $\beta$} \\
\hline & 0,05 & 0,1 & 0,15 & 0,2 & 0,25 & 0,3 & 0,33 & 0,35 & 0,4 & 0,45 \\
\hline 1 & 81,74 & 82,44 & 80,41 & 77,64 & 77,07 & 79,68 & 79,08 & 80,80 & 82,45 & 78,34 \\
\hline 2 & 79,74 & 79,40 & 78,37 & 79,37 & 80,08 & 79,77 & 80,02 & 80,13 & 79,70 & 80,36 \\
\hline 3 & 77,63 & 78,10 & 78,09 & 82,78 & 78,72 & 80,75 & 82,16 & 81,79 & 80,43 & 77,45 \\
\hline 4 & 80,76 & 81,71 & 75,70 & 77,99 & 77,74 & 79,00 & 78,69 & 80,78 & 81,75 & 78,01 \\
\hline 5 & 79,40 & 82,08 & 80,44 & 78,72 & 81,09 & 82,05 & 79,47 & 77,67 & 79,33 & 79,08 \\
\hline 6 & 80,38 & 77,36 & 80,79 & 78,46 & 80,44 & 80,71 & 80,44 & 81,71 & 78,06 & 78,37 \\
\hline 7 & 78,02 & 80,43 & 81,11 & 81,46 & 80,77 & 80,06 & 75,34 & 82,75 & 83,10 & 79,74 \\
\hline 8 & 79,07 & 80,05 & 81,44 & 82,45 & 80,06 & 78,37 & 79,83 & 77,03 & 78,33 & 78,74 \\
\hline 9 & 82,38 & 78,75 & 81,79 & 79,68 & 77,01 & 80,74 & 81,45 & 77,02 & 79,07 & 81,45 \\
\hline 10 & 80,36 & 76,44 & 80,76 & 81,76 & 78,37 & 78,39 & 80,15 & 80,76 & 77,70 & 77,32 \\
\hline 11 & 77,74 & 82,74 & 79,46 & 78,47 & 80,09 & 79,38 & 78,69 & 79,69 & 80,45 & 80,37 \\
\hline 12 & 79,07 & 79,06 & 82,83 & 79,06 & 79,87 & 80,03 & 78,08 & 81,78 & 81,10 & 79,08 \\
\hline 13 & 79,36 & 78,66 & 82,16 & 79,07 & 80,78 & 81,40 & 80,39 & 78,36 & 81,83 & 80,01 \\
\hline 14 & 80,72 & 81,13 & 79,46 & 78,70 & 80,07 & 79,34 & 78,03 & 82,46 & 77,71 & 81,08 \\
\hline 15 & 80,74 & 81,38 & 79,71 & 83,46 & 77,38 & 79,45 & 79,40 & 78,69 & 79,39 & 77,06 \\
\hline 16 & 80,07 & 79,74 & 79,69 & 80,08 & 80,08 & 76,61 & 79,37 & 79,72 & 78,69 & 79,44 \\
\hline 17 & 79,79 & 78,68 & 79,67 & 79,45 & 80,43 & 79,75 & 78,70 & 79,70 & 79,08 & 79,67 \\
\hline 18 & 82,15 & 77,70 & 79,75 & 79,72 & 79,10 & 82,49 & 77,07 & 80,10 & 80,79 & 78,66 \\
\hline 19 & 80,07 & 78,36 & 78,36 & 80,74 & 81,79 & 80,76 & 81,45 & 78,68 & 81,07 & 80,72 \\
\hline 20 & 81,07 & 80,05 & 80,46 & 82,40 & 79,79 & 76,70 & 80,44 & 79,77 & 79,67 & 81,10 \\
\hline 21 & 77,79 & 79,84 & 80,72 & 78,40 & 79,05 & 79,34 & 82,45 & 80,10 & 80,83 & 77,70 \\
\hline 22 & 80,78 & 78,38 & 80,78 & 81,75 & 78,34 & 79,11 & 77,37 & 80,75 & 80,00 & 78,15 \\
\hline 23 & 78,13 & 78,70 & 81,75 & 79,08 & 80,05 & 79,45 & 82,41 & 78,39 & 79,36 & 81,13 \\
\hline 24 & 78,37 & 81,06 & 80,80 & 77,70 & 79,38 & 80,44 & 81,47 & 78,67 & 80,02 & 78,70 \\
\hline 25 & 79,40 & 79,06 & 81,07 & 78,75 & 80,09 & 80,69 & 80,38 & 80,70 & 80,36 & 80,10 \\
\hline 26 & 77,74 & 80,44 & 80,72 & 79,79 & 79,41 & 80,01 & 77,07 & 80,06 & 81,06 & 79,07 \\
\hline 27 & 79,41 & 80,08 & 79,37 & 77,70 & 78,77 & 79,45 & 80,10 & 78,37 & 77,76 & 79,38 \\
\hline 28 & 80,40 & 78,43 & 80,46 & 79,77 & 79,43 & 78,37 & 79,74 & 81,75 & 77,02 & 78,38 \\
\hline 29 & 79,68 & 79,00 & 81,41 & 76,74 & 81,76 & 80,72 & 78,40 & 80,11 & 77,71 & 77,36 \\
\hline 30 & 80,40 & 80,43 & 81,08 & 81,01 & 80,11 & 78,68 & 79,06 & 80,45 & 75,33 & 79,74 \\
\hline Rata-Rata & 79,75 & 79,66 & 80,29 & 79,74 & 79,57 & 79,72 & 79,56 & 79,96 & 79,64 & 79,19 \\
\hline
\end{tabular}


Dari hasi pengujian yang ditunjukan pada table 4 , nilai rata-rata akurasi tertinggi adalah 80.29, sehingga nilai $\beta$ yang digunakan pada metode VPRS adalah 0.15 .

\subsection{Seleksi Fitur}

Langkah awal pada proses seleksi fitur ini adalah membagi data set menjadi dua bagian atau dikenal dengan splitting data set. Data set dibagi menjadi dua bagian dengan jumlah yang sama yaitu $2 / 3$ data digunakan sebagai data latih dan $1 / 3$ data lainnya digunakan sebagai data uji. Proses seleksi fitur dilakukan pada data set latih, kemudian dilakukan reduksi data pada data set latih dan uji sesuai dengan fitur-fitur yang dipilih. Tabel 7 menunjukan fitur-fitur yang dipilih oleh MFS dan VPRS.

\begin{tabular}{cl} 
& \multicolumn{1}{c}{ Tabel 7. Hasil seleksi fitur } \\
\hline Metode Seleksi Fitur & \multicolumn{1}{c}{ Hasil Seleksi Fitur } \\
\hline MTF & age, cp, trestbps, chol, fbs, restecg, thalach, exang \\
VPRS & $c p$, chol, restecg, thalach, exang, oldpeak, slope, thal \\
MTF+VPRS & $\begin{array}{l}\text { age, cp, trestbps, chol, fbs, restecg, thalach, exang, oldpeak, } \\
\text { slope, thal }\end{array}$ \\
\hline
\end{tabular}

\subsection{Pembangkitan Aturan/Rule IF-THEN}

Pada tahap ini, langkah yang dilakukan adalah melakukan pembangkitan aturan/rule IFTHEN dengan menggunakan metode VPRS pada data set latih hasil seleksi fitur dengan MTF, VPRS dan penggabungan MTF \& VPRS. Spliting data set dilakukan untuk membagi data menjadi data set latih dan data set uji, data set latih digunakan untuk mencari pengetahuan dalam data, sedangkan data set uji digunaka untuk menguji data dengan cara mencocokan hasil pengetahuan dengan data.

Pada penelitian ini aturan/rules IF-THEN didapatkan menggunakan toolkit ROSE2 untuk metode VPRS dengan data yang digunakan adalah data set latih yang telah didiskrit. Untuk mendapatkan aturan/rules IF-THEN atau aturan keputusan untuk metode VPRS menggunakan toolkit ROSE2 dengan nilai $\beta=0.15$. Aturan/Rules IF-THEN yang dihasilkan ditunjukan pada Tabel 8, Tabel 9 dan Tabel 10.

Tabel 8. Aturan/rules data set metode seleksi fitur berbasis pakar (MTF)

\begin{tabular}{|c|c|}
\hline Rule & Aturan/Rules \\
\hline 1 & $(\mathrm{cp}=3) \&(\mathrm{chol}=0) \&($ exang $=0)=>($ class $=0)$ \\
\hline 2 & $($ chol $=0) \&($ thalach $=2) \&($ exang $=0)=>($ class $=0)$ \\
\hline 59 & $(\mathrm{cp}=2) \&(\mathrm{chol}=3) \&(\mathrm{fbs}=0) \&($ thalach $=2)=>($ class $=0)$ OR $($ class $=1)$ \\
\hline 60 & $\begin{array}{l}(\mathrm{cp}=4) \&(\mathrm{fbs}=0) \&(\text { restecg }=0) \&(\text { thalach }=3) \&(\text { exang }=0)=>(\text { class }= \\
0) \text { OR }(\text { class }=1)\end{array}$ \\
\hline
\end{tabular}

Tabel 9. Aturan/Rules data set metode seleksi fitur VPRS

\begin{tabular}{|c|c|}
\hline Rule & Aturan/Rules \\
\hline $\begin{array}{l}1 \\
2\end{array}$ & $\begin{array}{l}(\mathrm{cp}=2) \&(\text { chol }=0) \&(\text { thal }=3)=>(\text { class }=0) \\
(\text { thalach }=1) \&(\text { thal }=3)=>(\text { class }=0)\end{array}$ \\
\hline$\cdots$ & 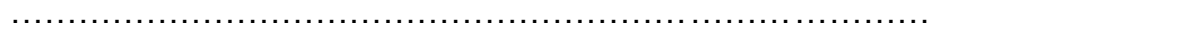 \\
\hline 54 & $(\mathrm{cp}=2) \&($ thalach $=2) \&($ slope $=2)=>($ class $=0)$ OR $($ class $=1)$ \\
\hline 55 & $\begin{array}{l}(\text { chol }=0) \&(\text { restecg }=2) \&(\text { thalach }=0) \&(\text { oldpeak }=0) \&(\text { slope }=1) \& \\
(\text { thal }=7)=>(\text { class }=0) \text { OR }(\text { class }=1)\end{array}$ \\
\hline & Tabel 10. Aturan/Rules data set metode seleksi fitur VPRS dan MTF \\
\hline Rule & Aturan/Rules \\
\hline 1 & $(\mathrm{cp}=2) \&(\mathrm{fbs}=0) \&($ thal $=3)=>($ class $=0)$ \\
\hline 2 & $(c p=3) \&($ thalach $=1) \&($ slope $=1)=>($ class $=0)$ \\
\hline $\begin{array}{l}\cdots \\
\cdots\end{array}$ & (2) \\
\hline
\end{tabular}


Jurnal IImu Teknik Elektro Komputer dan Informatika (JITEKI)

Vol. 3, No. 2, Desember 2017

$56 \quad(\mathrm{cp}=2) \&(\mathrm{chol}=3) \&(\mathrm{fbs}=0) \&($ thalach $=2)=>($ class $=0)$ OR $($ class $=1)$

57

$(\mathrm{fbs}=0) \&($ restecg $=2) \&($ thalach $=0) \&($ oldpeak $=0) \&($ slope $=1) \&$

$($ thal $=7)=>($ class $=0)$ OR $($ class $=1)$

\subsection{Evaluasi Performa}

Setelah didapat aturan-aturan/rules, pada penelitian ini aturan-aturan dengan menggunakan metode VPRS tersebut akan dilakukan pengujian terhadap data set uji menggunakan perangkat lunak Microsoft Excel untuk mendapatkan nilai akurasi pengujian aturan keputusan. Pengujian dilakukan terhadap 3 data set hasil seleksi fitur dengan MTF, VPRS dan MTF \& VPRS. Dari hasil pengujian rules maka didapatkan confusion matriks untuk masingmasing data set.

Tabel 11. Confusion matriks dari data set-data set hasil seleksi fitur

\begin{tabular}{crrrrc}
\hline \multirow{2}{*}{ Data set hasil seleksi fitur } & $\begin{array}{c}\text { Jumlah } \\
\text { Rules }\end{array}$ & TP & TN & FP & \multirow{2}{*}{ FN } \\
\hline VPRS & 55 & 51 & 33 & 15 & 0 \\
MFS & 60 & 51 & 35 & 13 & 0 \\
MFS+VPRS & 57 & 51 & 33 & 15 & 0 \\
\hline
\end{tabular}

Tabel 11 menunjukan komposisi nilai confusion matriks menggunakan penggabungan metode VPRS dengan RIPPER berupa nilai TP (True positive), TN (True Negative), FP (False Positive) dan FN (False Negative) dari 30 data set pengacakan. Nilai TP, TN, FP dan FN masing-masing data set tersebut digunakan untuk menghitung nilai akurasi, sensitivitas dan spesitivitas yang digunakan untuk menentukan diagnosis penyakit jantung koroner menggunakan metode VPRS.

Dari tabel confusion matriks dapat dihitung nilai akurasi setiap metode yang telah diterapkan berdasarkan data set - data set hasil seleksi fitur.

Tabel 12. Perbandingan nilai akurasi

\begin{tabular}{|c|c|c|c|}
\hline $\begin{array}{l}\text { Dataset hasil } \\
\text { seleksi fitur }\end{array}$ & $\begin{array}{c}\text { Nilai } \\
\text { Akurasi (\%) }\end{array}$ & $\begin{array}{c}\text { Nilai } \\
\text { Sensitivitas (\%) }\end{array}$ & $\begin{array}{c}\text { Nilai } \\
\text { Spesifisitas (\%) }\end{array}$ \\
\hline VPRS & 84,84 & 100 & 68,75 \\
\hline MFS & 86,86 & 100 & 72,91 \\
\hline MFS+VPRS & 84,84 & 100 & 68,75 \\
\hline
\end{tabular}

Dalam konteks medis hanya terdapat dua kelas yaitu "sakit" atau "sehat", dan kelas "sakit" lebih penting dibandingkan kelas "sehat". Tujuan dari diagnosis medis adalah fokus pada peningkatan akurasi kelas "sakit" atau sensitivitas dengan tetap menjaga akurasi pada kelas "sehat" atau spesifisitas. Dalam kasus diagnosis peyakit jantung koroner sensitivitas merupakan seberapa banyak pasien yang memiliki penyakit jantung koroner diprediksi benar memiliki penyakit jantung koroner.

\section{Kesimpulan}

Penelitian ini memberikan skema data mining untuk diagnosis penyakit jantung koroner dengan melakukan seleksi fitur dan klasifikasi menggunakan data set cleveland.

Dari penelitian ini beberapa poin dapat disimpulkan sebagai berikut:

1. Hasil diagnosis penyakit jantung koroner dengan seleksi fitur VPRS menghasilkan peningkatan nilai akurasi dibandingkan dengan diagnosis tanpa seleksi fitur yang telah dilakukan pada penelitian sebelumnya [12].

2. Metode seleksi fitur kombinasi VPRS dan MFS, menghasilkan Rules lebih sedikit dibandingkan dengan MFS, sedangkan untuk nilai akurasi untuk VPRS dengan kombinasi VPRS dan MFS mempunyai nilai akurasi yang sama yaitu $84,84 \%$.

Jadi dari hasil perbandingan proses pengujian menunjukan bahwa proses diagnosis penyakit jantung koroner dengan menggunakan metode seleksi fitur kombinasi VPRS dan MFS menunjukan nilai akurasi lebih baik dibandingkan tanpa menggunakan seleksi fitur [12] dengan jumlah rules dan atribut-atribut yang telah terseleksi sehingga atribut yang digunakan untuk mendiagnosis penyakit jantung koroner lebih sedikit yaitu atribut age, cp, trestbps, chol, fbs, 
Jurnal IImu Teknik Elektro Komputer dan Informatika (JITEKI)

Vol. 3, No. 2, Desember 2017

restecg, thalach, exang, oldpeak, slope, thal, dan tanpa menghilangkan atribut yang signifikan menurut pakar medis.

\section{Referensi}

[1] WHO, "Cardiovascular diseases (CVDs)," 2015. [Online]. Available: http://www.cdc.gov/heartdisease/. [Accessed: 05-Feb-2015].

[2] B. L. Zaret, M. Moser, and E. K. Hunt, Yale University School of Medicine Heart Book. New York, 1992.

[3] R. A. Pramunendar, I. N. Dewi, and H. Asari, "Penentuan Prediksi Awal Penyakit Jantung Menggunakan Algoritma Back Propagation Neural Network dengan Metode Adaboost," vol. 2013, no. November, pp. 298-304, 2013.

[4] T. J. Peter and K. Somasundaram, "Study and development of novel feature selection framework for heart disease prediction," Int. J. Sci. Res. Publ., vol. 2, no. 10, pp. 1-7, 2012.

[5] J. Soni, U. Ansari, D. Sharma, and S. Soni, "Predictive Data Mining for Medical Diagnosis: An Overview of Heart Disease Prediction," Int. J. Comput. Appl., vol. 17, no. 8, pp. 43-48, 2011.

[6] R. C. Holte, "Very simple classification rules perform well on most commonly used datasets," no. 1988 , pp. 63-91, 1993.

[7] M. Kumari and S. Godara, "Comparative Study of Data Mining Classification Methods in Cardiovascular Disease Prediction," ljcst, vol. 4333, no. 2229, pp. 304-308, 2011.

[8] W. W. Cohen, "Fast effective rule induction," Proc. Twelfth Int. Conf. Mach. Learn., pp. 115123, 1995.

[9] a H. Chen, S. Y. Huang, P. S. Hong, C. H. Cheng, and E. J. Lin, "HDPS: Heart disease prediction system," 2011 Comput. Cardiol., pp. 557-560, 2011.

[10] A. Rachman, A. B. Nurulniza, and C. P. Utomo, "Diagnosa Penyakit Jantung Menggunakan Teknik Automatic Post Pruning Decision Tree," J. Sist. Inf., vol. 5, no. 2, pp. 132-137, 2014.

[11] Dwi Wahyu Prabowo, "Seleksi Fitur Berbasis Komputer Untuk Diagnosis Penyakit Jantung Koroner," University of Gadjah Mada, 2014.

[12]D. Normawati, "Diagnosis penyakit jantung koroner menggunakan penambangan data berbasis variable precision rough set (vprs) dan repeated incremental pruning to produce error reduction (ripper)," university of gajah mada, 2015.

[13] C. T. Su and J. H. Hsu, "Precision parameter in the variable precision rough sets model: An application," Omega, vol. 34, no. 2, pp. 149-157, 2006.

[14]R. P. Sanjaya, "Deteksi Penyakit Jantung Koroner Menggunakan Model Variable Precision Rough Set dan Logika Fuzzy," University of Gadjah Mada, 2014.

[15] B. . Tripathy, D. . Acharjya, and V. Cynthya, "A Framework for Intelligent Medical Diagnosis Using Rough Set with Formal Concept Analysis," Int. J. Artif. Intell. Appl., vol. 2, no. 2, pp. 45-66, 2011.

[16] UCl, "Heart Disease Dataset," $2017 . \quad$ [Online]. Available: https://archive.ics.uci.edu/ml/machine-learning-databases/heart-disease/. [Accessed: 24Mar-2017].

[17] Fathul Ihsan and Noor Akhmad Setiawan, "Perbandingan Metode Diskretisasi Untuk Berbagai Macam Algoritma Machine Learning," University of Gadjah Mada, 2013.

[18] T. Herawan, W. Maseri, W. Mohd, and A. Noraziah, "Applying Variable Precision Rough Set for Clustering Diabetics Dataset."

[19]W. Ziarko, "Probabilistic Decision Tables in the Variable Precision Rough Set Model," Comput. Intell., vol. 17, no. 3, pp. 593-603, 2001.

[20] W. Ziarko, "Variable Precision Rough Set," 1993.

[21]W. Ziarko, "Variable precision rough set model," J. Comput. Syst. Sci., vol. 46, no. 1, pp. 3959, 1993.

[22] T. Fawcett, "An introduction to ROC analysis," Pattern Recognit. Lett., vol. 27, no. 8, pp. 861-874, 2006. 